\title{
Nanomole per Liter per Meter Squared
}

National Cancer Institute

\section{Source}

National Cancer Institute. Nanomole per Liter per Meter Squared. NCI Thesaurus. Code C119469.

A unit of concentration equal to nanomoles per liter, divided by meters squared. 